\title{
Effects of mold sealing and fiber volume fraction on properties of rice straw/unsaturated polyester biocomposites
}

\author{
Sakaowduen Preampree ${ }^{\mathrm{a}}$, Thanatorn Thanyapanich ${ }^{\mathrm{a}}$, Anyaporn Boonmahittsud ${ }^{\mathrm{b}}$, Uraiwan Intatha ${ }^{\mathrm{a}}$, \\ Nattaya Tawichai ${ }^{\mathrm{a}}$, Nattakan Soykeabkaew ${ }^{\mathrm{a}, *}$ \\ a Center of Innovative Materials for Sustainability (iMatS), School of Science, Mae Fah Luang University, \\ Chiang Rai 57100 Thailand \\ b Department of Materials Science, Faculty of Science, Chulalongkorn University, Bangkok 10330 \\ Thailand
}

*Corresponding author, e-mail: nattakan@mfu.ac.th

Received 16 Oct 2019

Accepted 12 Mar 2020

\begin{abstract}
In the past two decades, there has been a huge renewed interest in using natural fibers as reinforcements in composite materials due to growing concerns in the environment and sustainability. Rice straw is one of the agricultural wastes that has a good prospective to be used as a reinforcing agent owing to its abundance in Thailand. In this work, rice straw was used to reinforce with unsaturated polyester (UP) resin and the biocomposites were prepared by using a hot-compression molding technique. With heating involved and monomer loss concerned, firstly, the effect of using two different mold sets; (i) non-sealed mold and (ii) sealed mold during the forming and curing of biocomposites on their structures and mechanical properties was investigated. It was shown that the sealed mold resulted in the higher percentage of gel content or crosslinking degree of the UP matrix as well as an increase in the flexural properties of the biocomposites. This was supposedly due to the ability of the sealed mold to keep the UP system from excessive monomer loss during the heated curing reaction. Secondly, the effect of fiber (rice straw) volume fraction $\left(\mathrm{V}_{\mathrm{f}}\right)$ on the biocomposite performance was also studied. The results showed that the biocomposites with $\mathrm{V}_{\mathrm{f}}$ of 0.3 exhibited the highest strength and modulus values of $29.2 \pm 3.3 \mathrm{MPa}$ and $2.3 \pm 0.1 \mathrm{GPa}$, respectively. The SEM photos indicated a relatively good wettability and bonding between rice straw fibers and UP resin in this biocomposite structure.
\end{abstract}

KEYWORDS: biocomposites, rice straw, unsaturated polyester, processing step, fiber volume fraction

\section{INTRODUCTION}

Nowadays, natural fibers as well as agricultural waste fibers reinforced in thermosetting resin have increased steadily due to their green profiles. Rice straw is considered the most abundant agricultural waste in Thailand [1]. Most of rice straws are usually burned in agricultural fields by the farmers, thus causing serious air pollution, particularly fine particles (PM 2.5), which could dangerously lead to our long-term health problems [2]. However, the rice straw has several worthy characteristics for using as composite's reinforcement including its low density, goodstrength, renewability, and low cost $[3,4]$.

For composite industry, unsaturated polyester resin (UP) is the most common thermosetting polymer and also widely used as a resin to make biocomposites with natural fibers. This resin cures into the cross-linked network polymer by a rapid addition copolymerization of unsaturated groups in the polyester with styrene monomer in the reactive diluent. It does not soften and cannot be reshaped after cured. In order to produce composite materials with good mechanical properties, it is important to properly cure the resin and optimize their processing step [5]. Moreover, fiber volume fraction and interfacial bonding are important factors affecting mechanical properties of composites [6]. In case of long natural fiber composites, the matrix combines the fibers together, holding them in uni-directional or multi-directional alignment depending on the important stressed directions. For short fibers, the random orientation of fibers is normally the case. When load was applied to the composites, the matrix first took it and then transferred into the fiber reinforcement phase. Therefore, the reinforcing capacity of natural fibers to support loads of any kind 


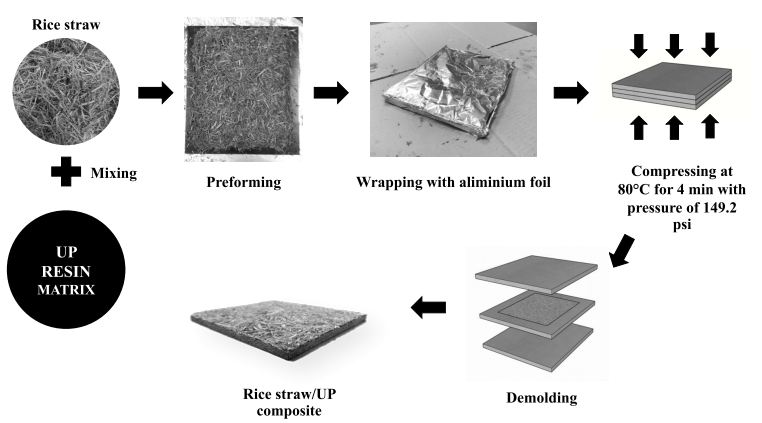

Fig. 1 Fabrication of the rice straw/UP composites by using compression molding technique.

is dependent on the presence of matrix as the loadtransfer medium, optimal fiber volume fraction as well as sufficient bonding between fiber and matrix phases $[7,8]$.

The present study aimed to, firstly, optimize processing procedure for fabricating the rice straw/UP biocomposites. Without heating or at normal room temperature, around $24 \mathrm{~h}$ under compression was needed for the voluminous preform of rice straw/UP to be harden and shaped into the composite panel. The high temperature with compression was, therefore, found to be necessary to shape this capacious preform into panels in short times (4 min). With heating involved and monomer loss concerned, the use of two different mold sets; (i) non-sealed mold and (ii) sealed mold during the forming and curing of biocomposites was attempted. Secondly, the effect of fiber (rice straw) volume fraction on the composite's structure and properties was also investigated. After fabricating, the prepared rice straw/UP biocomposites were characterized by using scanning electron microscopy, gel content determination method, and mechanical test.

\section{MATERIALS AND METHODS}

\section{Materials}

Rice straw (Oryza sativa L.) was harvested in a local agricultural field, Chiang Rai province, Thailand. It was size-reduced by using a grinder (Nimut Engineering Co., Ltd.), then dried in an oven at $100^{\circ} \mathrm{C}$ for $2 \mathrm{~h}$ and cooled down to room temperature. The average size of chopped rice straw was $32.44 \pm 24.2$ mm (Fig. 1). Unsaturated polyester resin (orthophthalic grade), using $1 \% \mathrm{v} / \mathrm{w}$ methyl ethyl ketone peroxide, MEKP, as a catalyst, with a density of $1.12 \mathrm{~g} / \mathrm{cm}^{3}$ were supplied by J.N. Transos Co., Ltd., Thailand. The properly casted and cured resin for $40 \mathrm{~h}$ at ambient atmosphere, followed by post- cure treatment at $120^{\circ} \mathrm{C}$ for $3 \mathrm{~h}$ was reported with the flexural strength of 120-125 MPa and flexural modulus of 4-4.3 GPa.

\section{Methods}

Firstly, the rice straw and UP resin were hand mixed together at the fiber and matrix volume fractions of 0.3:0.7 in a stainless steel bowl for $5 \mathrm{~min}$. Then, the voluminous mixture was preformed into a square metal mold (flash type) (Fig. 1). To ensure the proper curing, the 2 mold sets were used; (i) nonsealed mold and (ii) sealed mold with aluminum foil sheet. Then, the mold was placed in the hotpressing machine (Labtech Engineering Co., Ltd.), and compressed under pressure of $149.2 \mathrm{psi}$ at $80^{\circ} \mathrm{C}$ for $4 \mathrm{~min}$. It should be noted that this is the minimum time needed for the panel to be consolidated which was formerly tested in our experiment. After that, the composite panel was left at room temperature for $24 \mathrm{~h}$ and then demolded. From a naked-eye observation, the rice straw was randomly oriented in the obtained panels (Fig. 1). To study the effect of volume fraction of fiber, the composites were then prepared with different rice straw volume fractions, i.e., $0.1,0.2,0.3,0.4,0.5,0.6$ and 0.7 . The fiber volume fraction of the rice straw/unsaturated composites can be calculated with the following relation: $v_{f}=V_{f} / V_{c}$, where $v_{f}$ is the fiber volume fraction, $V_{f}$ is the volume of fiber $\left(\mathrm{cm}^{3}\right)$ and $V_{c}$ is the volume of composite $\left(\mathrm{cm}^{3}\right)$ [9].

\section{Characterization and testing}

\section{Morphology observation}

The fractured surfaces of composites were observed by a scanning electron microscope (SEM) (LEO/1450 VP) operated with a voltage of $10 \mathrm{kV}$. All samples were coated with a thin layer of gold by sputtering before the observation.

\section{Flexural test}

The flexural properties of the rice straw/UP composites were determined according to ASTM D790. The test was performed using a 3-point bending method. The testing machine (Instron model 5566) was equipped with $1 \mathrm{kN}$ load cell and operated at a cross-head speed of $2 \mathrm{~mm} / \mathrm{min}$. Dimension of the test specimens was $2 \pm 0.01 \mathrm{~cm} \times 10 \pm 0.01 \mathrm{~cm} \times 0.5 \pm 0.004 \mathrm{~cm}$ and the support span length was set at $8 \mathrm{~cm}[10]$. 


\section{Gel content determination}

The composite sample was cut into the dimension of $5 \pm 0.09 \mathrm{~mm} \times 5 \pm 0.09 \mathrm{~mm} \times 5 \pm 0.09 \mathrm{~mm}$ and kept at $23 \pm 2{ }^{\circ} \mathrm{C}$ for $40 \mathrm{~h}$ before the determination. Each sample was weighed and wrapped in a metal mesh pouch. The wrapped pouch was tied with a metal wire and then placed in a round-bottomed flask filled with $150 \mathrm{~mL}$ of tetrahydrofuran and then refluxed for $8 \mathrm{~h}$. Then, the wrapped pouch was dried at $80^{\circ} \mathrm{C}$ in an oven until constant weight. The gel content (\%) was determined using the following equations:

$$
\begin{aligned}
w_{\text {extracted }} & =w_{\text {(sample }+ \text { mesh }) \mathrm{be}}-w_{(\text {sample }+ \text { mesh }) \mathrm{ae}} \\
w_{\text {polymer }} & =w_{\text {sample }}-W_{\text {polymer }} \\
\% \text { Extraction } & =\frac{w_{\text {extracted }}}{w_{\text {polymer }}} \times 100 \\
\% \text { Gel content } & =100-\% \text { Extraction }
\end{aligned}
$$

where $w_{\text {extracted }}$ is the extracted weight, $w_{\text {sample }}$ is the weight of the composite, $w_{\text {(sample+mesh)be }}$ is the weight of composite and mesh before extraction, $w_{\text {(sample+mesh)ae }}$ is the weight of composite and mesh after extraction, $w_{\text {polymer }}$ is the weight of polymer, $W_{\text {polymer }}$ is weight fraction of polymer [11].

\section{RESULTS}

\section{Effect of mold sealing during the composite fabrication on their properties}

From Fig. 2(a), the rice straw/UP composite fabricated with sealed mold showed higher density $\left(0.97 \mathrm{~g} / \mathrm{cm}^{3}\right)$ when compared to that of the nonsealed mold $\left(0.93 \mathrm{~g} / \mathrm{cm}^{3}\right)$. The gel content measured in the composite prepared with sealed mold was also higher, $290 \%$, while it was around $82 \%$ for the one fabricated with non-sealed mold. Furthermore, the flexural strength and modulus of the composites with sealed mold were increased around $63 \%$ and $41 \%$, respectively, in comparison to those of the composite prepared with non-sealed mold (Fig. 2(b)). The stress-strain curves of the rice straw/UP composites with both non-sealed and sealed molds were plotted in Fig. 3. The composite fabricated with the sealed mold clearly exhibited the greater tensile properties (both stronger and stiffer) than the one with the non-sealed mold.

\section{Effect of fiber volume fraction on the composite properties}

The flexural properties of all fabricated composites with different rice straw volume fractions $(0.1-0.7)$
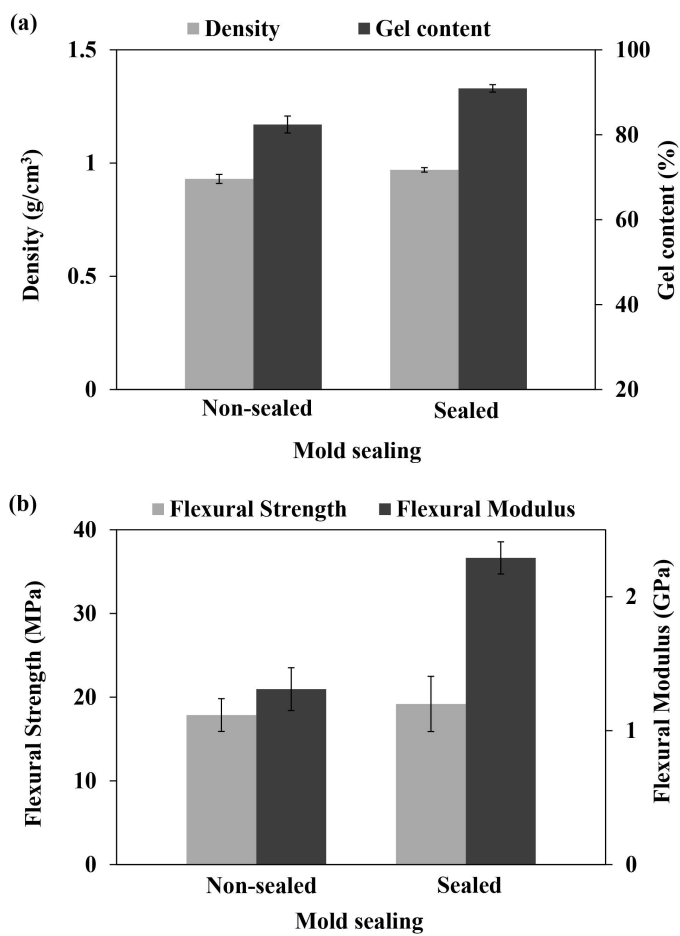

Fig. 2 (a) Density versus gel content and (b) flexural strength versus flexural modulus of the rice straw/UP composites prepared with non-sealed and sealed molds.

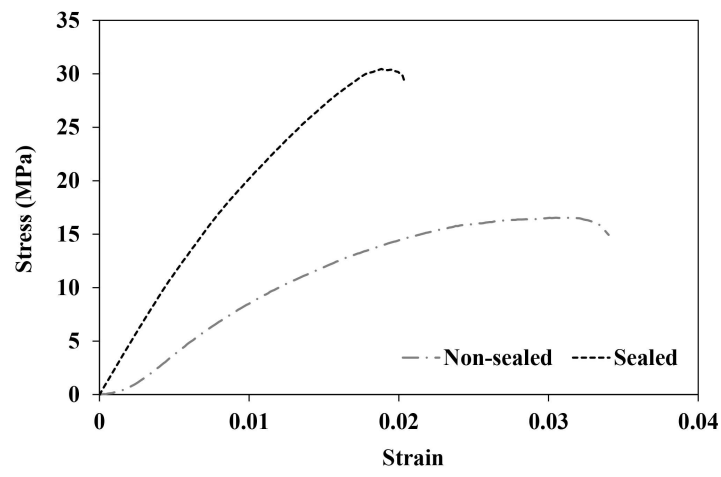

Fig. 3 Stress-strain curves of the rice straw/UP composites with different processing steps.

are shown in Fig. 4. It can be seen that the biocomposite with the fiber volume fraction of 0.3 had the highest strength and modulus of $29.19 \pm 3.30 \mathrm{MPa}$ and $2.29 \pm 0.12 \mathrm{GPa}$, respectively. When the fiber volume fraction in this biocomposites was increased to 0.4 and more, both flexural strength and modulus of the composites were noticeably decreased. SEM photos of the fractured surfaces of the composites 
Table 1 Density and mechanical properties of the rice straw/UP composites with different fiber volume fractions.

\begin{tabular}{lccccc}
\hline $\begin{array}{l}\text { Fiber volume } \\
\text { fraction }\end{array}$ & $\begin{array}{c}\text { Density } \\
\left(\mathrm{g} / \mathrm{cm}^{3}\right)\end{array}$ & $\begin{array}{c}\text { Specimen } \\
\text { weight }(\mathrm{g})\end{array}$ & $\begin{array}{c}\text { Flexural } \\
\text { strength }(\mathrm{MPa})\end{array}$ & $\begin{array}{c}\text { Flexural } \\
\text { modulus }(\mathrm{GPa})\end{array}$ & $\begin{array}{c}\text { Strain } \\
(\%)\end{array}$ \\
\hline 0.1 & $1.01 \pm 0.02$ & $222.2 \pm 4.4$ & $18.24 \pm 1.16$ & $1.47 \pm 0.12$ & $1.64 \pm 0.18$ \\
0.2 & $0.98 \pm 0.02$ & $215.6 \pm 4.4$ & $21.68 \pm 1.57$ & $1.96 \pm 0.13$ & $1.51 \pm 0.24$ \\
0.3 & $0.97 \pm 0.01$ & $213.4 \pm 2.2$ & $29.19 \pm 3.30$ & $2.29 \pm 0.12$ & $1.86 \pm 0.22$ \\
0.4 & $0.89 \pm 0.03$ & $195.8 \pm 6.6$ & $17.86 \pm 1.54$ & $1.73 \pm 0.07$ & $1.55 \pm 0.10$ \\
0.5 & $0.86 \pm 0.04$ & $189.2 \pm 8.8$ & $16.78 \pm 1.18$ & $1.68 \pm 0.22$ & $1.70 \pm 0.32$ \\
0.6 & $0.79 \pm 0.06$ & $173.8 \pm 13.2$ & $11.92 \pm 0.55$ & $1.16 \pm 0.18$ & $1.80 \pm 0.34$ \\
0.7 & $0.69 \pm 0.07$ & $151.8 \pm 15.4$ & $5.48 \pm 1.30$ & $0.62 \pm 0.14$ & $1.59 \pm 0.31$ \\
\hline
\end{tabular}

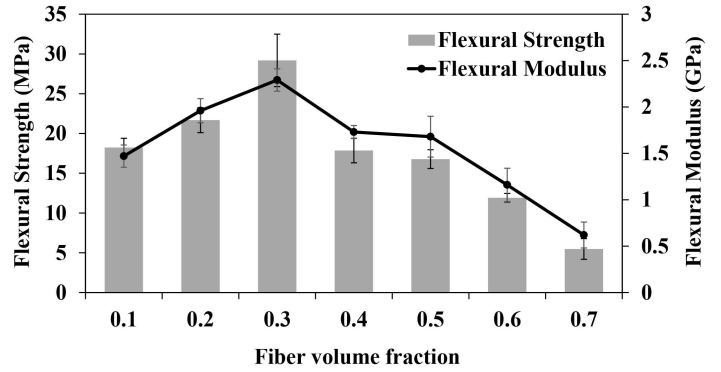

Fig. 4 Flexural strength and modulus of the rice straw/UP composites with different fiber volume fractions.

with different fiber volume fractions from 0.1-0.7 are gathered in Fig. 5(a-g). The embedded rice straw fibers in the UP resin matrix can be visibly perceived in the composites with lower fiber volume fractions $(0.1-0.3)$. The porosity in composites was noticed to increase with the increasing content of rice straw (0.4-0.7). Also, the longer pull-out fibers that were debonded from the matrix were also observed in the composites with higher fiber volume fractions. In line with SEM results, the density of the biocomposites was found to decrease with increasing fiber volume fraction (Table 1) since more voids and spaces were presented in their structures.

\section{DISCUSSION}

\section{Effect of mold sealing during the composite fabrication on their properties}

From the results comparing density and gel content of the composites prepared with non-sealed and sealed molds (Fig. 2(a)), we found that the mold sealing had a significant effect on anticipation of monomer loss during the fabrication. The higher density and gel content values of the biocomposite prepared with sealed mold indicated less monomer loss and higher crosslink fraction (gel) formed in this system. Hence, the denser compos- ite panel with higher degree of crosslinking could be gained $[12,13]$. Undoubtedly, this led to the improvement in flexural properties of the composite prepared with sealed mold (Fig. 2(b)) $[14,15]$. With denser structure and higher crosslinking of the matrix, the composite with sealed mold was shown to be much stiffer and stronger as expected (Fig. 3) since the denser crosslink network could restrict more of the polymer chain movement during composite deformation under applied force. Therefore, larger energy input was needed to bend or deform this composite, resulting in an increase in both its stiffness and strength $[16,17]$.

\section{Effect of fiber volume fraction on the composite properties}

The flexural properties of all fabricated composites with fiber volume fractions of $0.1-0.7$ are plotted in Fig. 4. The similar increasing and decreasing trends of the flexural strength and modulus were found when the fiber volume fraction of the composites was changed. At the fiber volume fractions of $0.1-0.3$, it showed that the addition of more fibers resulted in an improvement in the flexural properties of the composites as usually found in other composite systems $[18,19]$. The biocomposite with the fiber volume fraction of 0.3 showed the highest strength and modulus. In comparison with previous reports (Table 2), the properties of the current composites were slightly lower or comparable to other natural fiber/UP composites [20,21]. Since natural fibers are normally stronger than agricultural wastes, the inferior properties of the rice straw/UP composites are understandable [22]. If compared to the agricultural waste fiber system, polyester composites with $15 \mathrm{wt} \%$ treated bagasse addition, the prepared rice straw/UP composite with the fiber volume fraction of 0.2 in the present study showed the same level of strength but somewhat lower stiffness. After treated the bagasse fiber with alkaline solution, the flexural properties of this composites 


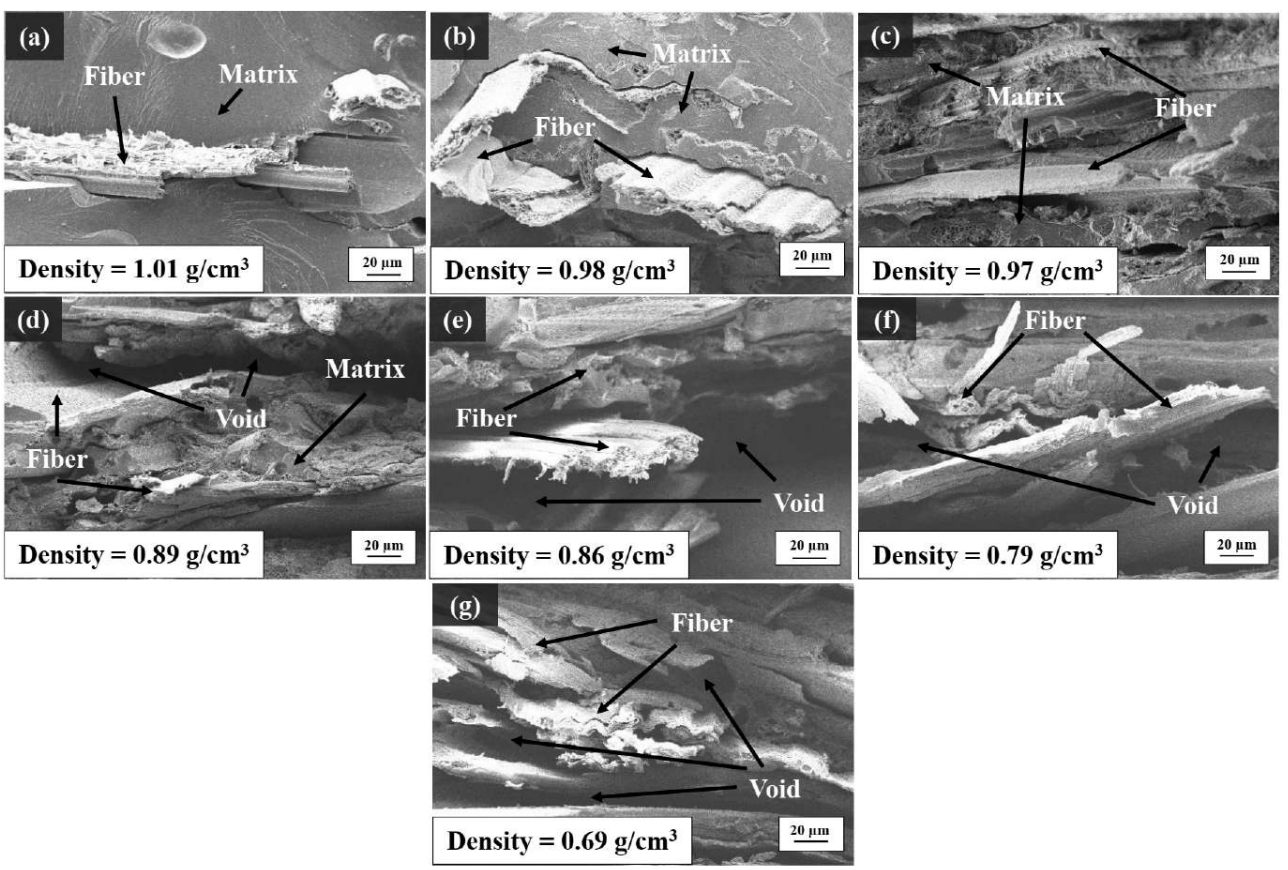

Fig. 5 SEM images of the biocomposites with (a) 0.1, (b) 0.2, (c) 0.3, (d) 0.4, (e) 0.5, (f) 0.6 and (g) 0.7 fiber volume fraction.

Table 2 Comparison of mechanical properties of different fibers reinforced in unsaturated/polyester composites.

\begin{tabular}{lcccl}
\hline Type of composite & $\begin{array}{c}\text { Fiber volume (v)/ } \\
\text { weight (wt) fraction }\end{array}$ & $\begin{array}{c}\text { Flexural } \\
\text { strength (MPa) }\end{array}$ & $\begin{array}{c}\text { Flexural } \\
\text { modulus (GPa) }\end{array}$ & Reference \\
\hline Rice straw fibers/UP & $0.3(\mathrm{v})$ & $29.19 \pm 3.30$ & $2.29 \pm 0.12$ & This work \\
Coir fibers/polyester & $0.3(\mathrm{v})$ & $29.00 \pm 3.78$ & $1.72 \pm 0.41$ & Prasad [20] \\
Sisal fibers/UP & $0.3(\mathrm{v})$ & $75.00 \pm 2.00$ & $3.50 \pm 0.10$ & Sangthong [21] \\
\hline Rice straw fibers/UP & $0.2(\mathrm{v})$ & $21.68 \pm 1.57$ & $1.96 \pm 0.13$ & This work \\
Bagasse/polyester & $0.15(\mathrm{wt})$ & 13.80 & 3.01 & Naguib [23] \\
Alkaline treated bagasse/polyester & $0.15(\mathrm{wt})$ & 22.20 & 3.40 & Naguib [23] \\
\hline
\end{tabular}

were increased due to the better interfacial bonding between fiber and matrix [23]. On the other hand, the addition of more than 0.3 volume fraction of rice straw resulted in a decrease in the flexural properties of the composites. It was likely due to an increasing porosity in the biocomposite structures (Fig. 5). This was because these systems had an insufficient amount of matrix to fill in and cover all fibers [24, 25]. Generally, the porosity in solid materials is highly related to a decline in their mechanical properties [26-28].

\section{CONCLUSION}

In this study, it was found that the mold sealing was crucial in fabricating this rice straw/UP composite system and could effectively increase the density and gel content of the resulting composite panels.
These increases indicated that monomer loss was largely reduced in the composite prepared with sealed mold, with the higher degree of crosslink network within the UP matrix. Thus, this resulted in a significant improvement in all flexural properties of the composite fabricated with sealed mold as compared to another composite with non-sealed mold. Furthermore, the optimum fiber volume fraction of rice straw for this composite system was found to be 0.3 , providing the highest flexural strength $(29.19 \pm 3.30 \mathrm{MPa})$ and modulus $(2.29 \pm 0.12 \mathrm{GPa})$ values of the biocomposite. The SEM images revealed that with further increasing rice straw volume fraction, the porosity in the composite structures was noticeably increased and, hence, abruptly decreasing mechanical properties of these composites as a result. 
Acknowledgements: Financial supports from National Science and Technology Development Agency (NSTDA), STEM Workforce Project and Center of Innovative Materials for Sustainability (iMatS), Mae Fah Luang University are gratefully acknowledged. We would like to thank $\mathrm{P}$ Win Intertrading Co., Ltd. for their kind supports of the metal molds and suggestions.

\section{REFERENCES}

1. Gadde B, Menke C, Wassmann R (2009) Rice straw as a renewable energy source in India, Thailand, and the Philippines: Overall potential and limitations for energy contribution and greenhouse gas mitigation. Biomass Bioenerg 33, 1532-1546.

2. Tipayarom D, Oanh NK (2007) Effects from open rice straw burning emission on air quality in the Bangkok metropolitan region. Scienasia 33, 339-345.

3. Sato A, Soeprijanto S, Widjaja A (2019) Influence of alkaline hydrothermal pretreatment of rice straw on biomass composition. Int Energy $J$ 19, 115-124.

4. Sheng J, Ji D, Yu F, Cui L, Zeng Q, Ai N, Ji J (2014) Influence of chemical treatment on rice straw pyrolysis by TG-FTIR. IERI Procedia 8, 30-34.

5. Zhang J, Liu J, Liang W, Qiao X, Zhou Q (2018) Overview of preparation methods for high performance composite materials. IOP Conf Ser Mater Sci Eng 394, ID 022058.

6. Cripps D, Searle TJ, Summerscales J (2000) Open mold techniques for thermoset composites. In: Kelly A, Zweben C (eds) Comprehensive Composite Materials, Elsevier, Amsterdam, pp 737-761.

7. Magdi EM (2013) Theoretical analysis of natural fiber volume fraction of reinforced composites. Alex Eng $J$ 52, 301-306.

8. Pan N (1993) Theoretical determination of the optimal fiber volume fraction and fiber-matrix property compatibility of short fiber composites. Polym Compos 14, 85-93.

9. Chung DDL (2017) Polymer-matrix composites: Structure and processing. Carbon composites. In: Neikov OD, Naboychenko SS, Yefimov NA (eds) Handbook of Non-Ferrous Metal Powders 2nd edn, Elsevier, Amsterdam, pp 161-217.

10. ASTM (2003) D790-03, Standard Test Methods for Flexural Properties of Unreinforced and Reinforced Plastics and Electrical Insulating Materials, ASTM International, PA.

11. Mokhothu TH (2010) Preparation and characterization of natural fibre/co-polyester biocomposites. $\mathrm{PhD}$ thesis, Univ of the Free State, South Africa.

12. Yang SL, Wu ZH, Yang W, Yang MB (2008) Thermal and mechanical properties of chemical crosslinked polylactide (PLA). Polym Test 27, 957-963.

13. Franck AJ (2004) Understanding rheology of thermosets. TA Instrum AAN 15, ID 14.

14. Jones FR (2017) Unsaturated polyester resins. In:
Gilert M (ed) Brydson's Plastics Materials 8th edn, Butterworth-Heinemann, Oxford, pp 743-772.

15. Aktas A, Krishnan L, Kandola B, Boyd SW, Shenoi RA (2015) A cure modelling study of an unsaturated polyester resin system for the simulation of curing of fibre-reinforced composites during the vacuum infusion process. $J$ Compos 49, 2529-2540.

16. Kausar A (2017) Role of thermosetting polymer in structural composite. Am J Polym Sci 5, 1-12.

17. Kalita D, Netravali AN (2017) Thermoset resin based fiber reinforced biocomposites. In: Mittal KL, Bahners T (eds) Textile Finishing: Recent Developments and Future Trends 1st edn, Wiley-Scrivener, Miami, pp 423-484.

18. Ismail MR, Yassen AA, Afify MS (2011) Mechanical properties of rice straw fiber-reinforced polymer composites. Fiber Polym 12, 648-656.

19. Ali-Eldin SS (2013) Mechanical properties of rice straw and rice straw-glass fiber reinforced epoxy composites. Egypt Int J Eng Sci Technol 16, 1631-1646.

20. Prasad SV, Pavithran C, Rohatgi PK (1983) Alkali treatment of coir fibres for coir-polyester composites. J Mater Sci 18, 1443-1454.

21. Sangthong S, Pongprayoon T, Yanumet N (2009) Mechanical property improvement of unsaturated polyester composite reinforced with admicellartreated sisal fibers. Compos Part A Appl Sci Manuf 40, 687-694.

22. Dungani R, Karina M, Subyakto AS, Hermawan D, Hadiyane A (2016) Agricultural waste fibers towards sustainability and advanced utilization: A review. Asian J Plant Sci 15, 42-55.

23. Naguib HM, Kandil UF, Hashem AI, Boghdadi YM (2015) Effect of fiber loading on the mechanical and physical properties of green bagasse-polyester composite. J Radiat Res Appl Sci 8, 544-548.

24. Nagaraja GB, Sugumaran P, Sridhar R (2012) Mechanical properties of rice straw and chicken feather fibers. Int J Compos Mater Manuf 2, 22-26.

25. Mohammadi H, Mirmehdi S, Hugen LN (2016) Rice straw/thermoplastic composite: Effect of filler loading, polymer type and moisture absorption on the performance. CERNE 22, 449-456.

26. Mehdikhani M, Gorbatikh L, Verpoest I, Lomov SV (2019) Voids in fiber-reinforced polymer composites: a review on their formation, characteristics, and effects on mechanical performance. J Compos Mater 53, 1579-1669.

27. Tran LQN, Minh TN, Fuentes CA, Chi TT, Van VAW, Verpoest I (2015) Investigation of microstructure and tensile properties of porous natural coir fibre for use in composite materials. Ind Crops Prod 65, 437-445.

28. Prasad AV, Rao K, Kumar MA, Rao KM (2006) Flexural properties of rice straw reinforced polyester composites. Indian J Fibre Text Res 3, 335-338. 